was to simulate a range of policy-relevant calorie-reduction interventions to measure the impact on obesity and inequalities.

Methods The predicted probability of obesity at age 11 was estimated using marginal structural models adjusted for total calorie consumption, as calculated from three-day diet diaries at age 7 years, and other baseline and intermediate confounding using data from Avon Longitudinal Study of Parents and Children $(n=10,680)$. Socioeconomic inequalities were indicated using maternal social class and assessed using odds ratios for absolute and relative inequalities. Complete case and multiple imputation analyses were conducted to manage survey attrition and missing data. A series of probabilities were estimated by manipulating the mediator to simulate daily caloriereduction interventions, including targeted and informed scenarios.

Results Using imputed data and adjusting for inequalities and confounding, $18.3 \%$ of children were living with obesity at 11 years. Maternal social class at baseline and total daily calories at 7 years significantly predicted obesity at 11 years. A simulation to reduce intake down to recommended levels, a $6 \%$ reduction in daily calories, universally applied but with random variation, reduced overall obesity prevalence by $0.8 \%$ with the greatest decrease observed among the lowest social class, meaning this intervention would reduce inequalities. Targeted interventions by income led to variations in reductions by social group. Informed interventions for children with overweight or obesity, or for children who ate excess calories daily, both at age 7 reduced obesity prevalence at age 11 by $0.9 \%$ and $1.5 \%$ respectively.

Conclusions A universal decrease in total daily calories to the recommended daily limit would reduce childhood obesity and inequalities but disproportionate uptake targeted across SES would have little impact on the overall effect. Informed interventions to reduce caloric intake among children who ate excess calories daily, or with overweight or obese at age 7 , would be effective at reducing obesity and inequalities.

\section{P44 ADOLESCENT SEXUAL ACTIVITY, CONTRACEPTIVE USE AND PREGNANCY IN BRITAIN AND THE UNITED STATES: A CROSS-NATIONAL COMPARISON}

${ }^{1} \mathrm{R}$ Scott, ${ }^{2} \mathrm{~K}$ Wellings, ${ }^{3} \mathrm{~L}$ Lindberg*. ${ }^{1}$ Department of Population Health, London School of Health and Tropical Hygiene, London, UK; ${ }^{2}$ Department of Public Health, Environments and Society, London School of Health and Tropical Medicine, London, UK; ${ }^{3}$ Research, Guttmacher Institute, New York, USA

\subsection{6/bmjpo-2019-RCPCH-SAHM.48}

Aims Pregnancy rates among adolescents have declined in the US and Britain, but remain high compared to other highincome countries. This comparison examines trends in pregnancy rates, recent sexual activity and contraceptive use among women aged $16-19$ in the US and Britain to consider the behavioural drivers of the decline in pregnancy rates in the two countries and the differences between them.

Methods We use data from two rounds of the US National Survey of Family Growth, conducted 2002-3 and 2011-15, and the British National Survey of Sexual Attitudes and Lifestyles, conducted 2000-2001 and 2010-2012, to examine differences between countries and over time in sexual activity and contraceptive use. We calculate pregnancy rates using national births and abortions data.
Results Pregnancy rates declined in both countries from 2001 to 2013 (US 45\%, England and Wales 33\%; this decline began earlier in the US and was steeper. In the later period a higher proportion of adolescents in Britain than the US reported ever having sex (GB 65\% v. US 49\%), sex in the last six months $(59 \%$ v. $39 \%)$ and four weeks (48\% v. $29 \%)$ and using highly-effective contraception (68\% v. 52\%). Between the two time periods there was no change in sexual activity in Britain, but in the US the proportion reporting recent sex declined. In both countries, there was a shift towards more effective contraception. IUD and implant use increased from $1 \%$ to $13 \%$ in Britain and from less than $1 \%$ to $5 \%$ between 2002 and 2013 ( $\mathrm{p}<0.001)$. Pill, ring and patch use declined in Britain (58\% to $49 \%, \mathrm{p}=0.02)$, but did not change in the US. No method use declined only in the US $(8 \%$ to $4 \%)$. Neither country had changes in condom or withdrawal use.

Conclusions In both countries, improvements in contraceptive use appear the main driver of the decline in pregnancy rates. Comparing Britain and the US shows that more sex among young people does not have to mean more pregnancies, and supports expanding comprehensive sex education programmes and youth-friendly contraceptive services in both countries.

\section{P45 SMOKING AND DRINKING BEHAVIOUR OF BISSAU- GUINEAN ADOLESCENTS AGED 15-16 COMPARED TO EUROPEAN PEERS}

${ }^{1} \mathrm{G}$ Gunnlaugsson*, ${ }^{2} \mathrm{~A}$ Baldé, ${ }^{3} \mathrm{Z}$ Jandi, ${ }^{1,3} \mathrm{H}$ Boiro, ${ }^{3} \mathrm{JR}$ Butiam Có, ${ }^{1} \mathrm{~J}$ Einarsdóttir. ${ }^{1}$ Sociology, Anthropology, and Folkloristics, University of Iceland, Reykjavik, Iceland; 'Jean Piaget University Guinea-Bissau, Bissau, Guinea-Bissau; ${ }^{3}$ Institute of Education and Research (INEP), Bissau, Guinea-Bissau

\subsection{6/bmjpo-2019-RCPCH-SAHM.49}

Aims With the Sustainable Development Goals 2016-2030 increased attention is given to adolescents' health and wellbeing, and the multiple challenges they face related to their health and wellbeing with trajectories of importance for their later adult health. A recent trend within childhood and youth studies acknowledges commonalities of lived experiences of young people in middle- and low-income countries, where the majority of them lives, vis-à-vis high-income countries. In subSaharan Africa adolescents comprise $23 \%$ of the population compared to $12 \%$ in high-income countries. Here we describe and analyse the prevalence of smoking and use of alcohol by Bissau-Guinean adolescents aged 15-16 and compare to peers European cities.

Methods Survey with locally adapted and pilot tested Planet Youth questionnaire was conducted in June 2017 in 16 secondary schools in the capital Bissau, Guinea-Bissau. It targeted adolescents aged 15-16 years in randomly selected classes with information that is comparable with data from eight European cities in 2015-2016.

Results In Bissau, 871 adolescents aged 15-16 participated (52\% girls and $46 \%$ boys) compared to 6,534 peers in eight European cities (49\% girls and 51\% boys). In total, $2.2 \%$ of the Bissau-Guineans reported daily smoking (boys $=3.9 \%$; girls $=0.7 \%$ ) compared to $11.3 \%$ of their European peers (boys $=13.2 \%$; girls=9,4\%). About $1 / 3$ of the Bissau Guineans had life-time experience of drinking alcohol compared to about $2 / 3$ of the European ones, with no difference among boys and girls; $10,6 \%$ of Bissau-Guineans reported having been drunk during the last 30 days compared to $14 \%$ of the 
Europeans, the prevalence being slightly higher among boys compared to girls.

Conclusions Bissau-Guinean adolescents aged 15-16 report less smoking and drinking than European peers. Against a background of intensive marketing of alcohol and tobacco in Guinea-Bissau, it is urgent to initiate health promotional activities in secondary schools in Bissau to inform and educate adolescents and teachers on the detrimental effect of such behaviours on their long-term health and wellbeing.

\section{P46 ESTABLISHMENT OF A COMMUNITY YOUTH LEADERSHIP COUNCIL TO PROMOTE AND FACILITATE YOUTH-CENTERED HEALTH CARE DELIVERY IN A LARGE METROPOLITAN CITY}

${ }^{1} \mathrm{E}$ Uy-Smith*, 'A Labat, ${ }^{2} \mathrm{D}$ Polanco-Mendoza, ${ }^{1} \mathrm{Y}$ Teitel, ${ }^{2} \mathrm{~K}$ Morrison, ${ }^{1} \mathrm{M}$ Tapia. ${ }^{1}$ Department of Family and Community Medicine, University of California, San Francisco, San Francisco, USA; ${ }^{2}$ Community Health Programs for Youth, San Francisco Department of Public Health, San Francisco, USA

10.1136/bmjpo-2019-RCPCH-SAHM.50

Patient engagement has been touted by the Institute of Medicine as integral to effective and coordinated healthcare delivery. Scant literature exists regarding successful models of youth engagement within healthcare. In order to better address the health needs of youth in a large metropolitan city, a unique collaboration between two long-standing community health centers aims to advance youth-centered health care delivery through the establishment of a community youth leadership council (YLC). With seven decades of community engagement and health service delivery between the two clinics, the creation of the YLC is a synergy of strategic goals from both health centers. Using the expertise of the YLC, we will build upon the existing partnership between the clinics to help link this vulnerable demographic into a university-affiliated primary care medical home based on a public hospital campus. We ultimately aim to improve youth enrollment in healthcare, address health disparities in sexually transmitted infections (STIs) and healthcare utilization, and design a healthcare environment particularly welcoming to those who have been most isolated from accessing it. The YLC will assist us in establishing formal linkages with youth-facing organizations, as well as serving as consultants in creating a framework to increase pathways to primary care. We constructed a participatory process that will engage youth leaders in developing mechanisms to facilitate access for less-connected youth. Adding a community youth-operated and youth-focused cohort to the patient advisory council process will address the lack of a youth-centered perspective in clinic improvements and referral processes. Recruitment for potential YLC members was done through local high schools, clinics, and online social media. A total of 40 youth applications were received via an online- and paper-based application process. For the first three YLC meetings, at least 15 youth were in attendance at each monthly meeting. Currently planned YLC projects include standardized patient training for the youth, clinic beautification projects, and school-based 'pop-up' clinics. By bringing healthcare to the forefront of our youth's lives, the collaboration between two community health centers and the public school system will uniquely allow the youth of this large metropolitan city to transform healthcare delivery and access.

\section{P47 UNDERSTANDING THE CHALLENGES FACED BY ADOLESCENTS AND YOUNG ADULTS WITH ALLERGIC DISEASE: A SYSTEMATIC REVIEW}

${ }^{1} \mathrm{G}$ Roberts ${ }^{*},{ }^{2} \mathrm{M}$ Vazquez-Ortiz, ${ }^{3} \mathrm{~L}$ Angier, ${ }^{4} \mathrm{~N}$ Blumchen, ${ }^{5} \mathrm{P}$ Comberiati, ${ }^{2} \mathrm{~B}$ Duca, ${ }^{6} \mathrm{~A}$ DunGalvin, of EAACl Adolescent and Young Adult Task Force. 'University Child Health, University of Southampton, Southampton, UK; ${ }^{2}$ Paediatric Allergy, St Mary's Hospital, London, UK; ${ }^{3}$ Primary Care, University of Southampton, Southampton, UK; ${ }^{4}$ Pediatric Allergy, University Hospital Frantfurt, Frankfurt, Germany; ${ }^{5}$ Section of Paediatrics, University of Verona, Verona, Italy; ${ }^{6}$ Applied Psychology and Paediatrics and Child Health, University College Cor, Cork, Eire

\subsection{6/bmjpo-2019-RCPCH-SAHM.51}

Aims This systematic review aims to understand the challenges faced by adolescents and young adults (11-25 years) with allergic diseases, including asthma.

Methods A search strategy was constructed using Cochrane Database of Systematic Reviews, MEDLINE, Embase and Psychinfo. Databases were searched to February 10, 2019. Quality assessments and data extraction were undertaken independently by two reviewers.

Results 108 papers describing 106 studies were included. Most were from USA $(n=50)$, Netherlands $(n=12)$, Sweden $(n=11)$ and UK $(n=11)$. Most focused on asthma $(n=69)$ or food allergy $(n=19)$. They were qualitative, cross-sectional or longitudinal quantitative studies. There were five themes. ${ }^{1}$ Quality of life, as a measure of patients' experience of life. Factors associated with impaired quality of life: symptomatic disease, impaired psychological health, onset in adolescence, poor adherence, female sex and multiple allergies. Protective factors were exercise and increasing age. ${ }^{2}$ Psychological factors. Social anxiety has been associated with asthma and food allergy; it may inhibit patients from using medication in front of peers. Depression has also be associated with asthma and food allergy while suicidal ideation has been associated with eczema. Emotional support from family and friends has been found to be protective for asthma control. ${ }^{3}$ Adherence. Factors associated with poor adherence are older age; barriers to using medication such as lack of time, forgetfulness, cost, competing demand and accessibility, over reliance on short-acting rescue medication or poor knowledge; lack of perception of symptoms; and lack of personal responsibility. Factors associated with good adherence were routine, good self-efficacy, simple medication regimes and good knowledge about their disease. Patients who need to carry self-injectable adrenaline seem to be particularly non-adherent; the burden of these and incorrect knowledge around risks leading to poor decision making. ${ }^{4}$ Self-management. This extended from the previous theme and involved a series of barriers and corresponding facilitators. ${ }^{5}$ Supportive relationships. Key ones were identified as families, peers, friend and schools and healthcare professionals.

Conclusion The current evidence base to support the planned European guidelines for managing allergic disease in this age group is weak. Large longitudinal cohort and interventional studies are required to strength the evidence base. 